\title{
AMALIA 5: ROL DE LOS PAISAJES LAGUNARES EN LA CIRCULACION HUMANA EN EL INTERIOR DE LA ESTEPA FUEGUINA
}

\section{AMALIA 5: THE ROLE OF SHALOW LAKE LANDSCAPES IN HU- MAN CIRCULATION IN THE INLAND OF THE FUEGIAN STEPPE}

\author{
Jimena Oría ${ }^{1}$, Mónica Salemme ${ }^{2}$ y Marilén Fernández ${ }^{3}$ \\ 1 CADIC-CONICET. E-mail: jimenaoria@hotmail.com. \\ 2 CADIC-CONICET y UNTDF. E-mail: msalemme@cadic-conicet.gob.ar \\ 3 CADIC-CONICET. E-mail: shanamain@gmail.com \\ Presentado el: 20/09/2013/ - Aceptado el: 07/05/2014
}

\begin{abstract}
Resumen
Nueva evidencia arqueológica proveniente del interior de la estepa del norte de Tierra del Fuego es considerada desde una perspectiva regional. Un conjunto de piezas líticas recuperadas en la costa de la laguna Amalia se analizó contemplando los patrones distribucionales del registro arqueológico en la localidad y contrastando con la evidencia disponible para el sector costero. El propósito es aportar a la discusión de los modelos planteados sobre el uso del espacio, particularmente en relación a la recurrencia ocupacional en determinados puntos del paisaje.
\end{abstract}

Palabras claves: Circulación humana, Lagunas someras, Estepa fueguina, Holoceno

\begin{abstract}
New archaeological evidence coming from the inland steppe of northern Tierra del Fuego is analyzed from a regional viewpoint. An assemblage recorded along the coasts of the shallow lake Amalia has been studied under the analysis of distributional patterns, and it is compared to the available evidence regarding the Atlantic coastal area. The aim is to discuss the current models on the use of the space, particularly in relation to the occupational redundancy in specific places of the landscape.
\end{abstract}

Key words: Human circulation, Shallow lakes, Fuegian steppe, Holocene 


\section{Introducción}

Las localidades arqueológicas de la costa Atlántica en el norte de Tierra del Fuego han sido el foco de numerosas investigaciones acerca de los modos de vida y adaptaciones preeuropeas en dicha área. Esas localidades vinculadas con la costa marina actual y paleocosta del Holoceno corresponden a ocupaciones de cazadores-recolectores pedestres, aunque se explotaron recursos costeros en proporciones significativas.

Trabajos desarrollados en el área han planteado una diferencia costa-interior en relación al registro arqueológico (Urrejola Dittborn 1971; Borrero 1985; Massone et al. 1993; Ocampo y Rivas 1996). Los sitios más grandes, que implican una base residencial con una ocupación de mayor duración y en algunos casos con evidencias de reocupación, se encuentran en la costa o en relación con ésta; esto marca un registro arqueológico de mayor (o alta) visibilidad. Para el interior se describe un patrón de "campamentos de corta duración, presentándose un gradiente desde la zona estepárica (...), donde predominan los campamentos efímeros, hasta la costa (...), donde los asentamientos habrían tenido una mayor duración y una ocupación más frecuente" (Ocampo y Rivas 1996:147).

Por su parte, en el área interior ${ }^{1}$ también se han registrado sitios relevantes tanto por su cronología (Tres Arroyos 1, Myren 2, Figura 1) como por sus características (Cabeza de León 1 -con Bloque Errático 1 como satélite-, Las Vueltas 1 y San Julio 1 y 2, Lago Vergara y Laguna Larga, LA12, Figura 1). Estos son los únicos casos de sitios "no costeros" con material en estratigrafía, excavados, con fechados radiocarbónicos y analizados a nivel regional (Saxon 1976; Borrero 1979; Borrero y Casiraghi 1980; Borrero et al. 1981; Massone 1987; Massone et al. 1993; Horwitz et al. 1993/1994; Prieto et al. 2007; Santiago 2013; Morello et al. 2012).

En la zona de bahía Inútil, Massone (1997) ha propuesto una ocupación continua, evidenciada por la distribución homogénea de hallazgos aislados, con una mayor concentración en la franja costera y especialmente en las proximidades de las desembocaduras de los ríos Marazzi y Torcido, aunque también registra concentraciones de sitios en relación a los cursos medio e inferior de los ríos y en las lomas interiores. Las características de estos sitios concuerdan con lo observado por Ocampo y Rivas (1996). Los sitios de mayor extensión considerados lugares de asentamiento de varias jornadas y probablemente de uso reiterado se registran todos en el sector costero. Los sitios correspondientes a "campamentos efímeros", en los que se efectuaron actividades logísticas específicas se localizan, en su mayoría, en el interior. Estas diferencias en los tipos y funcionalidades de los sitios en relación a su emplazamiento expresarían un uso diferencial de los sectores costeros e interior de la estepa. Algunos autores (Urrejola Dittborn 1971; Ocampo y Rivas 1996) plantean que el bajo registro en el sector interior de la estepa está enfatizado, además, por la mala visibilidad.

Para el sector argentino las evidencias que aportaron gran parte de los estudios dieron cuerpo al modelo de movilidad inicialmente planteado por Borrero (1985), quien postula que, en el norte de la isla en momentos tardíos, entre 1000-100 años AP, aproximadamente, se habría dado un patrón de alta movilidad residencial y baja intensidad ocupacional. El tamaño pequeño y la distribución de los sitios del interior avalan la alta movilidad y la falta de necesidad de acudir a lugares de campamento pautados. Para la costa, las concentraciones de sitios en ciertos puntos sugieren la existencia de factores de localización muy estrictos (Borrero 1985). 


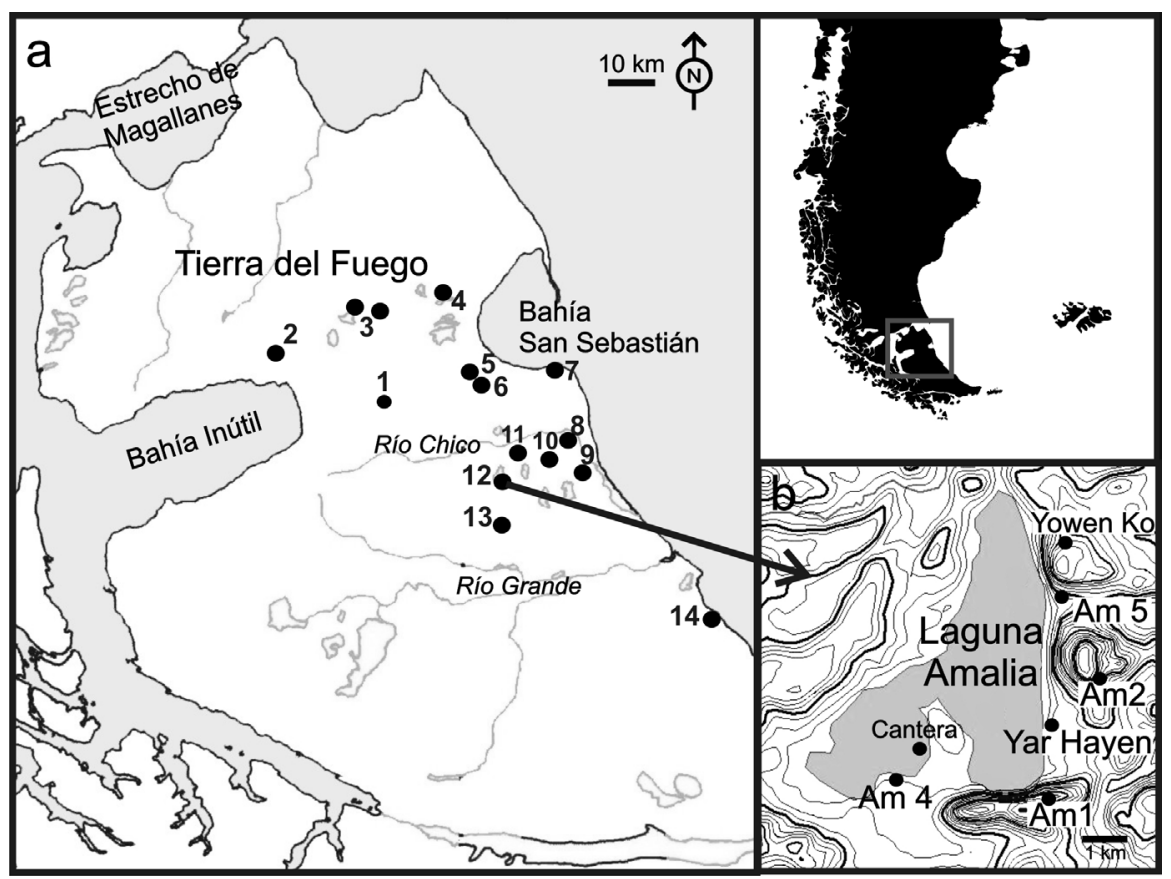

Figura 1. Ubicación aproximada de sitios y localidades mencionadas en el texto; (a) norte de Tierra del Fuego; (b) detalle laguna Amalia (Am: Amalia). Referencias: 1. Tres Arroyos 1; 2. Myren 2; 3. Lago Vergara y Laguna Larga; 4. LA12; 5.Cabeza de León; 6. Bloque Errático 1; 7. Los Chorrillos; 8. Río Chico 1; 9. La Arcillosa; 10. Las Vueltas 1; 11. Chacra Pafoy; 12. Laguna Amalia; 13. San Julio 1 y 2; 14. Punta María.

Las diferencias en densidades y tamaños de sitios que han permitido plantear patrones de movilidad no reflejan una economía volcada a los recursos marinos. La mayoría de los sitios, incluso los costeros, registran mayor proporción de recursos terrestres con un uso más bien complementario de alimentos de origen marino (Borrero 2008; Santiago et al. 2011). Evidencias vinculadas a circulación de materias primas líticas y a la información isotópica en restos humanos permiten plantear un modelo más complejo en relación con el uso del espacio donde el sector interior de la estepa fueguina cumple un rol significativo (Borrazzo et al. 2008). Para el sector comprendido en el istmo formado entre las bahías San Sebastián-Inútil, la diferencia en la composición artefactual y las materias primas registradas -así como la intensidad en el empleo de las mismas- permite sostener un modelo de alta movilidad con ocupaciones cortas pero que incluye componentes logísticos (Borrazzo et al. 2008 y bibliografía allí citada).

Hacia el sur, en el área comprendida entre las cuencas de los ríos Chico y Grande de la isla Grande de Tierra del Fuego, la estructura del registro arqueológico se ha analizado desde una perspectiva distribucional y geoarqueológica (Santiago 2013; Oría 2012). En este sentido, se considera al registro como un continuum con picos de mayor densidad artefactual (Dunnell y Dancey 1983) que refleja la actividad humana en ambientes amplios y no sólo en focos donde pudo desarrollarse una actividad determinada. Al abordar el estudio de grupos cazadores-recolectores de alta movilidad, resulta útil el análisis de patrones que reflejen cómo esas poblaciones circulaban en el espacio en relación a los rasgos 
del paisaje como medio físico. En este sentido, en el área de estudio se ha registrado un patrón vinculado a las lagunas que sugiere un uso intenso y heterogéneo de los ambientes interiores (Oría 2012; Oría et al. 2010a, 2010b).

En este marco, el objetivo de este trabajo es evaluar, el registro arqueológico del sitio Amalia 5, y el rol que pudieron haber ejercido las lagunas en el esquema de alta movilidad propuesto, contemplando las características ambientales. Se aporta a la discusión sobre el uso del espacio, proponiendo la ocupación recurrente en determinados puntos del paisaje.

\section{Un espacio y un lugar}

La forma en que los grupos se mueven en el espacio responde a motivaciones relacionadas con cuestiones de subsistencia o de índole ideológico o social que, en muchos casos, escapan a la materialidad del registro. Desde la Arqueología del Paisaje, Muir (1999) en referencia a los conceptos lugar y paisaje, plantea que ambos son definidos por la experiencia y los valores de quienes los habitan; el paisaje como el medioambiente percibido y el lugar como parte de las redes sociales que allí se dan (Muir 1999).

Desde un enfoque más ecosistémico, Stafford y Hajic (1992) definen "elementos del paisaje" como ecosistemas discretos que representan espacios donde un atributo es homogéneo: la geoforma, el suelo, la vegetación, etc. Estos elementos pueden considerarse como unidades analíticas desde las cuales definir la estructura del paisaje. La frecuencia y distribución espacial de esos puntos - considerados como "stopping points" (Stafford 1995:73) - pueden influir en las estrategias de movilidad de los grupos cazadores-recolectores, generando un patrón de uso del espacio y, en consecuencia, la estructura espacial del registro arqueológico (Stafford 1995).

El concepto de espacio, como espacio cargado de significación (lugar) y como "stopping point", se plantea como una vía para explorar en el registro arqueológico la forma en que los grupos humanos se movieron en el ambiente. Conocer la distribución de artefactos en las geoformas que tienen el potencial para funcionar como "stopping points", y los cambios ambientales que pueden afectar esa potencialidad, ayuda a comprender los procesos que generaron la distribución espacial del registro arqueológico en el paisaje (Stafford 1995). Esos procesos tienen que ver con las estrategias de movilidad a nivel regional. Qué conduce a que determinados puntos en el paisaje manifiesten mayor reincidencia ocupacional, no necesariamente tiene una vinculación con la subsistencia del grupo; puede tener una explicación desde la significación social que convierte ese espacio particular en un lugar (Tilley 1994; Muir 1999).

\section{El paisaje local: Laguna Amalia}

La estepa fueguina es una unidad de vegetación que ocupa el norte de Tierra del Fuego y es equivalente a la estepa magallánica húmeda en su porción continental. El aspecto que presenta es homogéneo, predominando un paisaje abierto de extensas llanuras y mesetas recortadas, con una cubierta vegetal de especies herbáceas y arbustivas (Oliva et al. 2001). El viento fuerte y constante constituye su rasgo singular.

Geoformas que se distinguen en este tipo de paisajes son las lagunas, que se caracterizan por ser salobres, temporarias y de tamaños variables. En muchas de ellas se observa la formación de una duna en la margen este como producto de la acumulación eólica 
(Figura 2; Coronato et al. 2011). Las costas de estas lagunas fueron lugares estratégicos en el pasado para el funcionamiento de sociedades cazadoras-recolectoras (Oría 2012), donde se concentrarían recursos como guanacos y aves al igual que materia prima lítica (Oría y Pal 2011; Oría et al. 2010b).

Dentro de este grupo de lagunas, Laguna Amalia se destaca por su dimensión. Ciertas características de esta laguna en relación a su formación y a los cambios experimentados a lo largo del tiempo aún permanecen desconocidos. Evaluar ciertos parámetros físicos y químicos como $\mathrm{pH}$, conductividad, temperatura y salinidad actuales del cuerpo lacustre, así como analizar muestras de diatomeas en el agua, contribuyen a ofrecer una primera aproximación a la caracterización del paleoambiente.

A partir del relevamiento del área, se presenta aquí el caso de una localidad arqueológica donde se han registrado siete sitios (Figura 1b) y se ha interpretado como un espacio de ocupación redundante. Se analiza en detalle el sitio Amalia 5 (Figura 2c).

\section{Materiales y métodos}

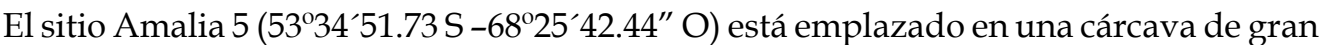
tamaño que se abre en la costa este de la laguna (Figuras 1 y 2). El perímetro del mismo fue calculado en $2000,5 \mathrm{~m}$, delimitando un área de $51.022 \mathrm{~m}^{2}$.

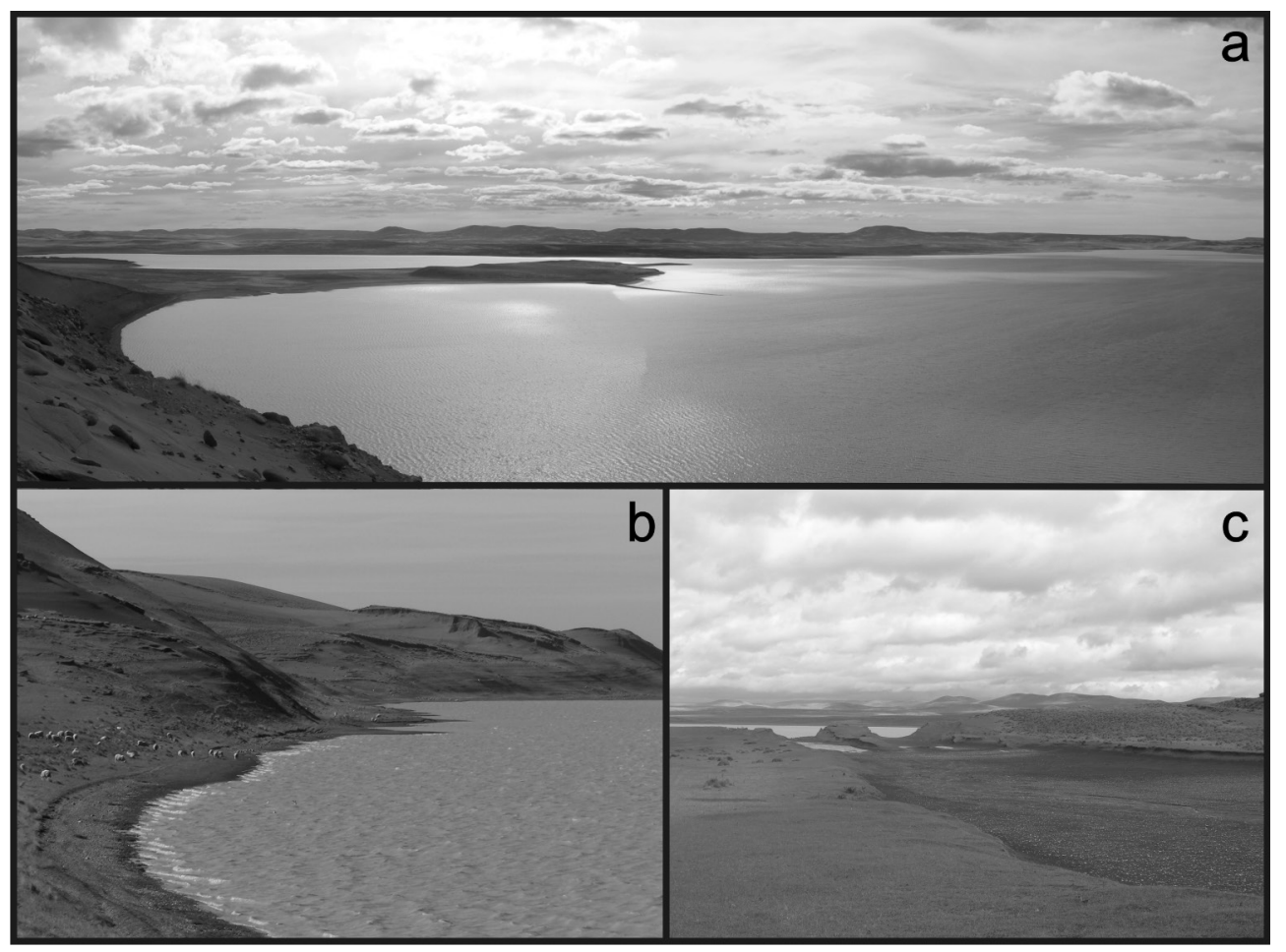

Figura 2. Paisaje en laguna Amalia; (a) costa sur con península; (b) costa este con acumulaciones eólicas y (c) detalle de la cárcava en la cual se emplaza el sitio. 
Tras evaluar las dimensiones de la cárcava y estimar la cantidad de materiales expuestos, se resolvió recuperar el material utilizando Estación Total para tomar los datos referidos a su localización. Se trazaron líneas rectas perpendiculares a la cárcava cada 20 metros y se registró el total de los materiales por banda, pero solo se recuperó el material de las bandas impares, dejando in situ los identificados en las bandas pares para posteriores mediciones. En la figura 3 se muestra la delimitación de las bandas y la distribución de los materiales recuperados, un total de 214 artefactos (Tabla 1). Al aproximarse a la laguna, la superficie deflacionada de la cárcava se angosta y los materiales describen un patrón más denso, que se vincula con los procesos de formación de la misma. La forma en que la distribución de materiales se ajusta a la morfología de la cárcava refuerza la posición secundaria de estos materiales. La acción del viento levanta nubes de polvo transportando el sedimento expuesto en sentido oeste-este y, a su vez, la incidencia del escurrimiento de agua profundiza la cárcava desplazando los materiales arqueológicos.

Para el análisis de los materiales líticos se siguieron los lineamientos generales de Aschero (1975) y Orquera y Piana (1986). Las variables analizadas fueron: categoría artefactual, materia prima, dimensiones (largo, ancho y espesor, medido en $\mathrm{mm}$ ), tamaño, peso en

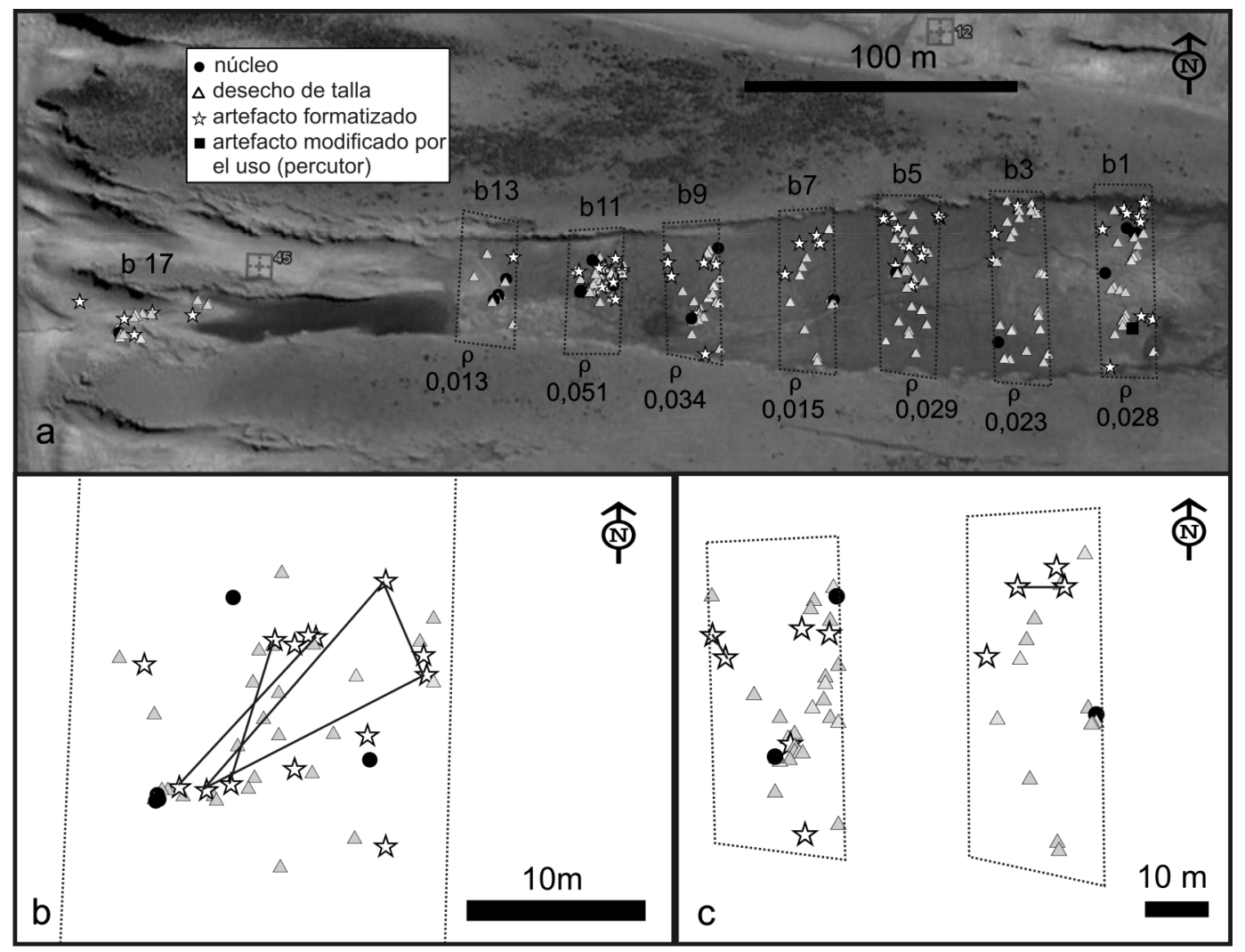

Figura 3. Distribución de materiales registrados en Amalia 5; a) distribución general por categorías artefactuales y densidad de artefactos por $\mathrm{m}^{2}$, por banda; b) detalle concentración densa de materiales en banda $11 ; c$ ) detalle bandas 9 y 7 . Las líneas en b y c señalan reparaciones; los casos de las bandas 7 y 9 (Figura 3c) son los que registraron reactivación. 


\begin{tabular}{|c|c|c|c|c|c|c|c|}
\hline \multirow{2}{*}{\multicolumn{2}{|c|}{ Categoría artefactual }} & \multicolumn{6}{|c|}{ Materias Primas } \\
\hline & & $\begin{array}{l}\text { Rocas } \\
\text { silici- } \\
\text { ficadas }\end{array}$ & $\begin{array}{l}\text { Rocas } \\
\text { riolí- } \\
\text { ticas }\end{array}$ & $\begin{array}{l}\text { Rocas } \\
\text { grani- } \\
\text { toides }\end{array}$ & Sílex & Indet. & Total \\
\hline \multirow{3}{*}{$\begin{array}{c}\text { artefacto con } \\
\text { formatización } \\
\text { primaria }\end{array}$} & núcleo & 9 & 10 & 0 & 1 & 0 & 20 \\
\hline & lasca & 50 & 51 & 0 & 2 & 7 & 110 \\
\hline & desecho ind. & 18 & 8 & 0 & 1 & 2 & 29 \\
\hline \multirow{5}{*}{$\begin{array}{l}\text { artefacto con } \\
\text { formatización } \\
\text { secundaria y } \\
\text { por pulido }\end{array}$} & raedera & 26 & 12 & 0 & 0 & 1 & 39 \\
\hline & raclette & 1 & 0 & 0 & 0 & 0 & 1 \\
\hline & $\begin{array}{l}\text { lasca c/retoques } \\
\text { sumarios }\end{array}$ & 4 & 2 & 0 & 0 & 0 & 6 \\
\hline & punta de arma & 4 & 0 & 0 & 0 & 0 & 4 \\
\hline & bola & 0 & 0 & 4 & 0 & 0 & 4 \\
\hline $\begin{array}{l}\text { artefacto con } \\
\text { rastros de uso }\end{array}$ & percutor & 0 & 1 & 0 & 0 & 0 & 1 \\
\hline \multicolumn{2}{|l|}{ Total } & 112 & 84 & 4 & 4 & 10 & 214 \\
\hline
\end{tabular}

Tabla 1. Composición artefactual por materias primas en Amalia 5 (ind.: indiferenciado; Indet.: Indeterminadas)

gramos y reserva de corteza (porcentaje de la misma). Para lascas y artefactos formatizados sobre lascas se constató además el estado de fragmentación y características referidas a la morfología de las lascas.

Las categorías artefactuales asignadas desde el análisis tecnomorfológico fueron para artefactos con formatización primaria: núcleos, lascas, desechos indeterminados; para artefactos con formatización secundaria: raederas, raclettes, bolas de boleadora y puntas de arma, sumándose lascas con retoques sumarios y los artefactos modificados por el uso representados por un percutor. Para el caso puntual de los núcleos se evaluó el tipo de núcleo, su forma base y su estado (agotado o sin agotar), siguiendo a Paulides (2006).

La materia prima se determinó macroscópicamente, utilizándose categorías litológicas amplias, según el esquema clasificatorio de Borrazzo (2010). Las categorías aquí utilizadas son rocas riolíticas (rocas volcánicas de textura porfírica y/o afanítica del extremo félsico), rocas basálticas (rocas volcánicas de textura afanítica y/o porfírica del extremo máfico), rocas silicificadas (rocas ígneas con textura afanítica o sedimentarias con textura pelítica, todas ellas con elevada proporción de sílice en su masa), rocas granitoides (rocas ígneas filónicas o plutónicas) y sílex (rocas de composición silícea y dominantemente afaníticas). Estas materias primas están disponibles regionalmente (Santiago et al. 2007a; Oría 2012) y se diferencian en calidad para la talla y en resistencia para la fragmentación (Aragón y Franco 1997).

Se registró el tamaño de todos los artefactos - enteros y fragmentados - utilizando una grilla de recuadros con categorías por tamaño que se incrementan cada $5 \mathrm{~mm}: 5 \mathrm{~mm}$ (superficie del recuadro $5 \times 5 \mathrm{~mm}$ ), $10 \mathrm{~mm}$ (superficie del recuadro $10 \times 10 \mathrm{~mm}$ ), $15 \mathrm{~mm}$ (superficie del recuadro 15 x 15 mm) y así sucesivamente (Franco 2002).

La reserva de corteza se cuantificó en porcentajes que van del $0 \%$-ausencia total- al $100 \%$ de la pieza, considerando entre ambos valores únicamente el 25\%, el 50\% y el 75\% de superficie con corteza. Se contempló la superficie total en núcleos, desechos indiferenciados o artefactos con formatización secundaria y la cara dorsal en lascas (Franco 2002). 
Respecto de la caracterización del ambiente cercano al sitio, se analizaron perfiles sedimentológicos de la cárcava en la que se emplaza el sitio (Figura 2c), para estudiar su contenido en diatomeas, considerando que es un proxy para interpretar las características ambientales.

\section{Resultados}

El conjunto analizado se caracteriza por un predominio de desechos de talla -incluidos lascas y desechos indiferenciados-, alcanzando un $n=139$ (65\% del conjunto) (Tabla 1). Los artefactos con formatización secundaria representan en conjunto un $25 \%(n=54)$. Dentro de este grupo, en varios casos se realizaron reparaciones (sensu Ramos y Merenzon 2004) (Figura $3 \mathrm{~b}$ y c): cuatro raederas fracturadas en dos partes y una fracturada en tres partes (Figura 4a). Como resultado, 11 ítems fueron reducidos a 5 raederas, modificándose con ello los $\mathrm{N}$ totales. En el análisis aquí presentado estas piezas se consideraron independientemente. No es posible saber en qué instancia se produjo la fractura, ni el tiempo transcurrido, pero en dos casos se registró reactivación post-fractura (Figura 4 b y c).

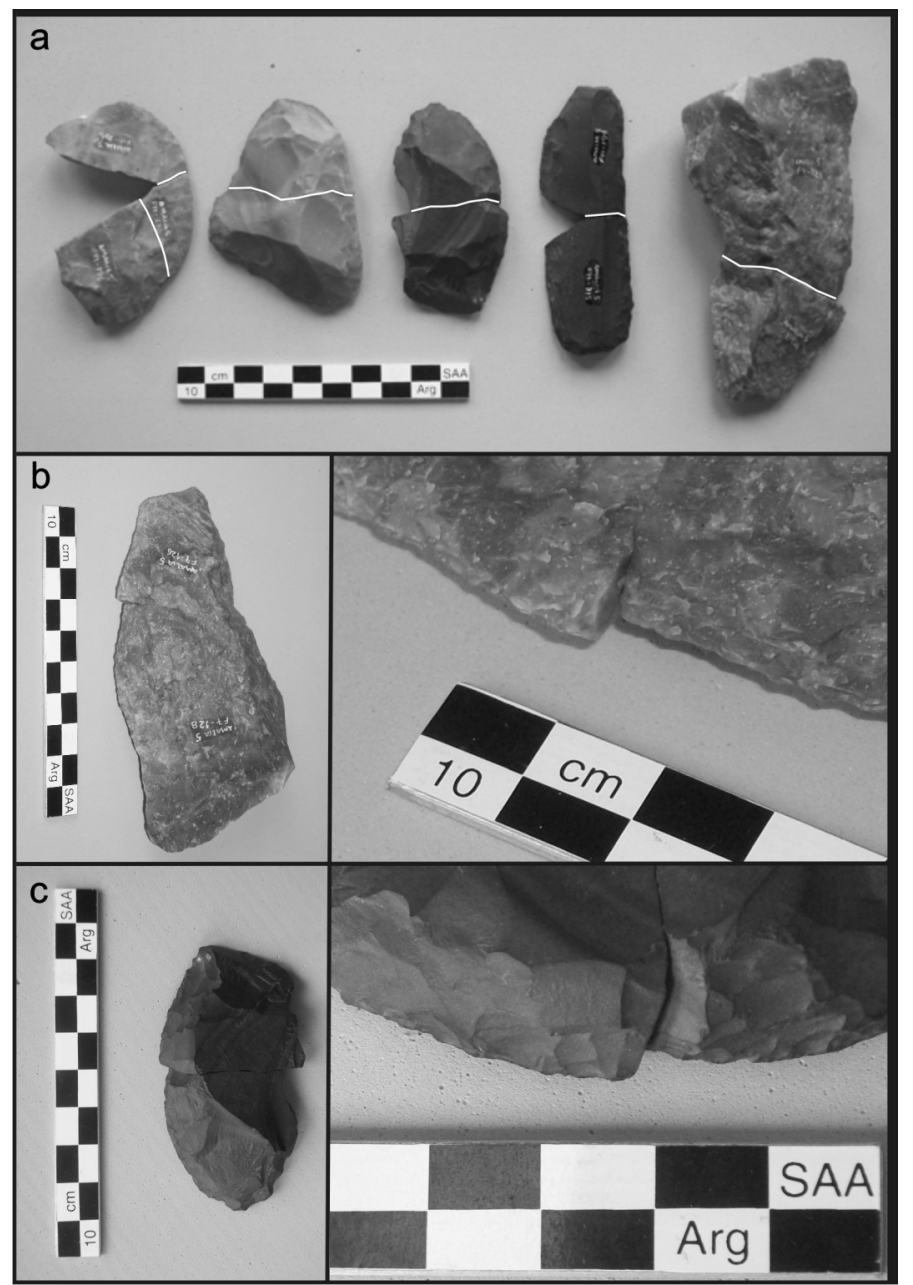

Figura 4. (a) raederas fracturadas y reparadas; las líneas blancas superpuestas destacan la fractura; (b) y (c) raederas con evidencias de reactivación. 


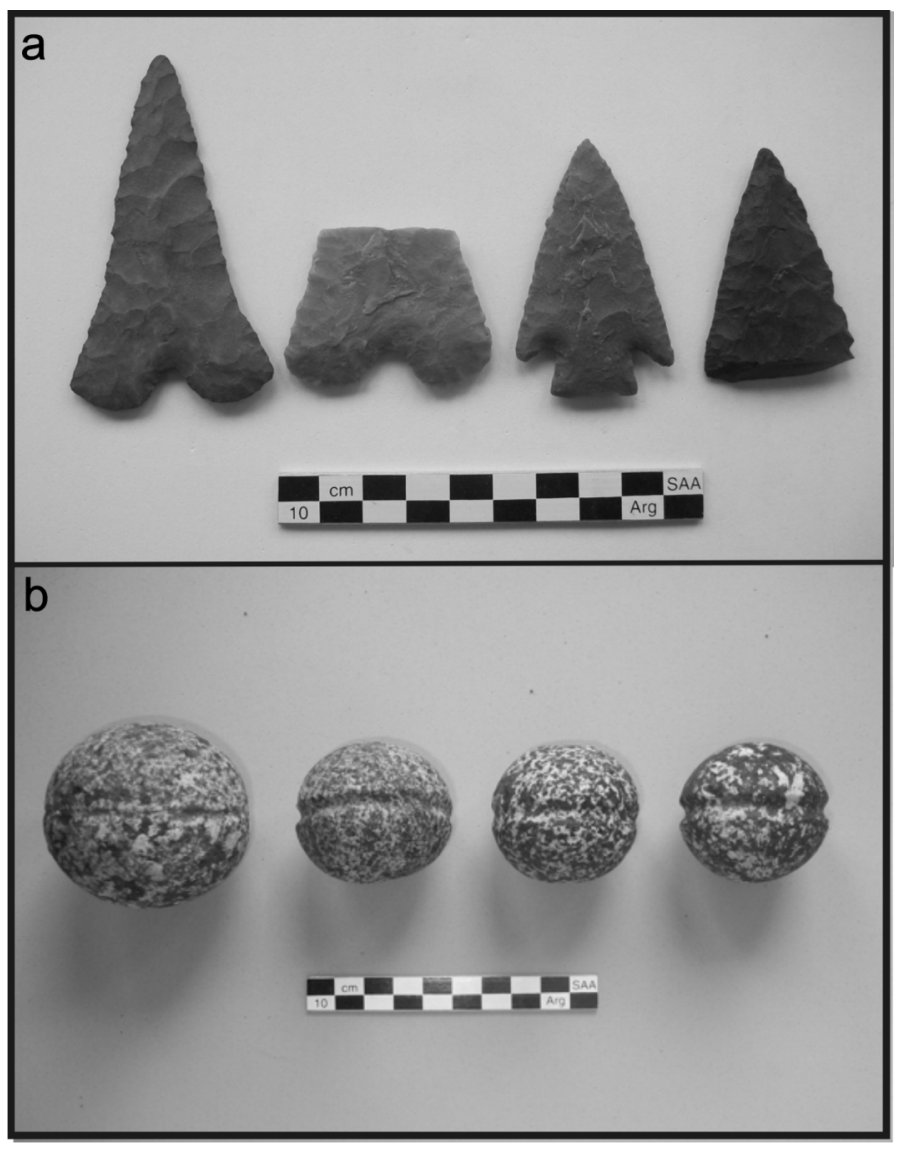

Figura 5. Artefactos recuperados en Amalia 5; (a) puntas; la del extremo izquierdo y el fragmento a su lado, de morfología aún no descripta; (b) bolas de boleadora.

El grupo tipológico más frecuente en artefactos formatizados son las raederas $(n=33$, contemplando las reparaciones), seguido de lascas con retoques sumarios $(n=6)$, puntas de arma y bolas ( $\mathrm{n}=4$ cada uno) y un raclette. En este conjunto no sólo llama la atención la cantidad de artefactos con formatización secundaria, sino que constituye el locus que contiene más cantidad de puntas de arma registrado en el área entre las cuencas de los ríos Chico y Grande (Figura 5a). No sólo es alta la frecuencia de puntas sino también la diversidad en sus diseños, registrándose en este contexto una morfología de punta aún no descripta regionalmente (F. Morello, K. Borrazzo, M. E. Mansur, M. Alvarez y A. F. Zangrando, com. pers.), tal como las dos ilustradas en el extremo izquierdo en la figura $5 a$.

A excepción de las bolas, confeccionadas todas ellas en tonalitas de distintos tamaños de grano (Figura $5 b$ ), agrupadas como rocas granitoides, predominan las rocas silicificadas en todas las categorías de artefactos con formatización secundaria. La selección de rocas silicificadas para la formatización por retoque probablemente se relacione con la calidad de estas rocas para la talla. 


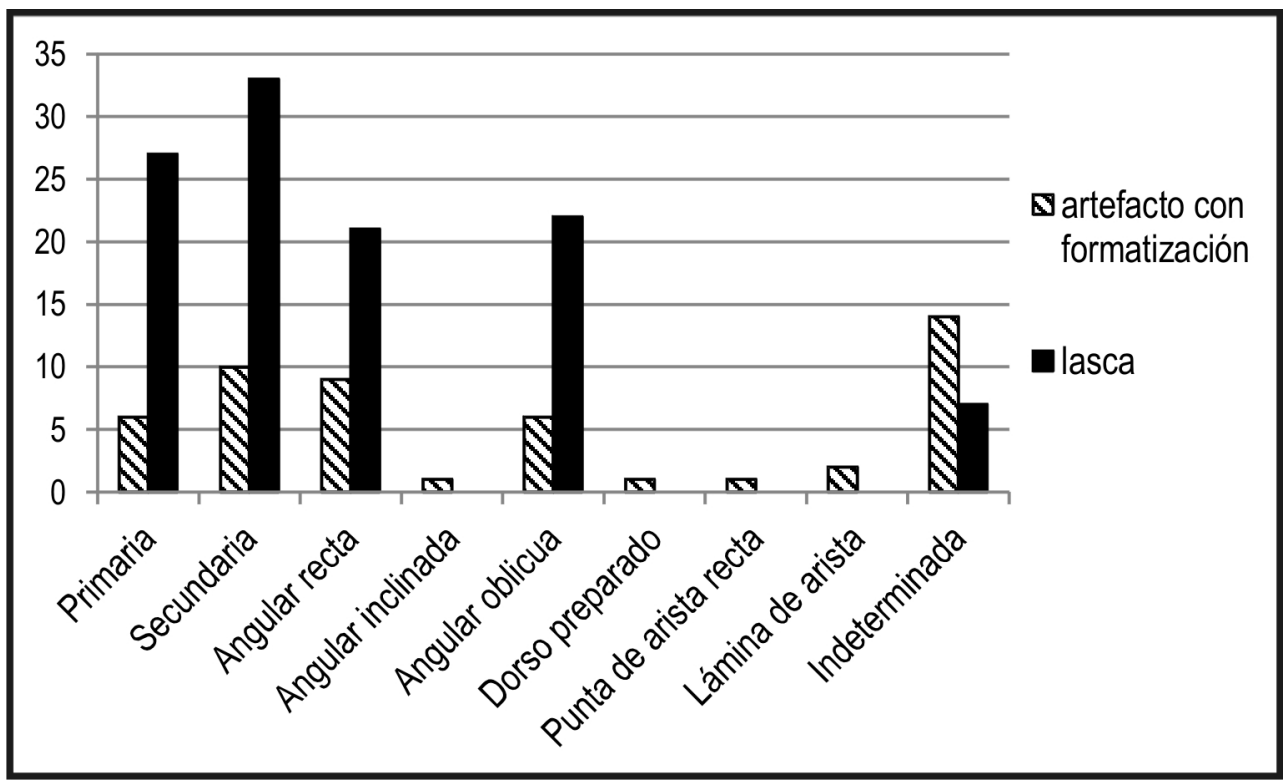

Figura 6. Tipos de lascas y láminas registrados, discriminando por categoría artefactual.

Existe un marcado predominio de lascas primarias y secundarias; sin embargo, entre aquellas que recibieron formatización por retoque se observa mayor variabilidad tipológica (Figura 6). La forma base de los núcleos es el rodado en todos los casos; predominan los núcleos con lascados aislados, especialmente en rocas silicificadas.

El 52\% del conjunto está compuesto por artefactos confeccionados en rocas silicificadas $(n=112)$, el $39 \%$ en rocas riolíticas $(n=84)$, un $4 \%$ se reparte entre rocas granitoides y sílex $(n=4$ cada uno) y en el $5 \%$ restante $(n=10)$ la materia prima no pudo ser identificada. Para analizar el grado en que se explotó cada materia prima se consideró la reserva de corteza en las piezas, notando que el $75 \%(n=160)$ de los materiales conserva corteza. Al analizar comparativamente los tipos de materia prima más utilizados, existe solo una mínima diferencia en la proporción de materiales con resto de corteza (Figura 7a).

En las lascas $(n=110)$ y artefactos formatizados sobre lascas $(n=50$, excluyendo las bolas) se evaluó el estado de fragmentación. El 59\% $(n=94)$ se recuperaron enteras (LENT), el $27 \%(n=44)$ se consignaron como fracturada con talón (LFCT) y un $14 \%(n=22)$ se encontró fracturada sin talón (LFST).

El estado de fragmentación se consideró en relación a la materia prima, notándose un predominio de piezas enteras en todos los tipos de rocas. Analizando comparativamente las materias primas más representadas, no se observa una diferencia muy marcada, aunque existe mayor proporción de fragmentación para rocas riolíticas (Figura 7b).

Los artefactos recuperados en Amalia 5, tanto los enteros como los fragmentados, muestran un rango de tamaños muy amplio, que va de 20 a $145 \mathrm{~mm}$, estando ausente algunas categorías (110, 130 y $135 \mathrm{~mm})$. Los tamaños más frecuentes están entre 25 y $80 \mathrm{~mm}(93 \%$ del conjunto); no se registraron piezas con tamaños inferiores a $20 \mathrm{~mm}$, ausencia que podría explicarse por pérdida de material en estos conjuntos de superficie. Desechos de talla y 


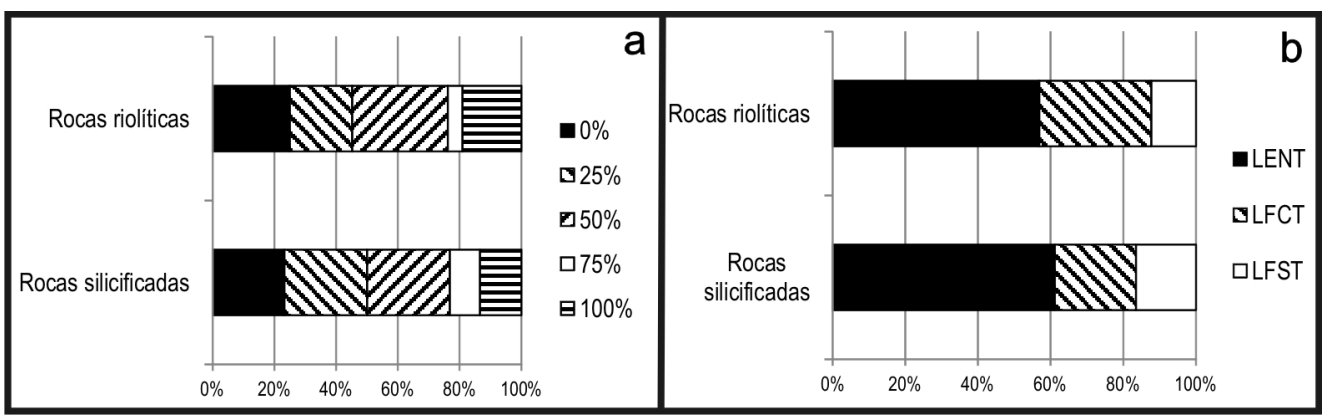

Figura 7. (a) Proporción de corteza para materiales de rocas riolíticas y silicificadas; (b) proporción de piezas enteras y fracturadas, discriminado por materia prima (LENT: lascas enteras; LFCT: lascas fracturadas con talón; LFST: lascas fracturadas sin talón).

artefactos formatizados comparten los mismos rangos y similares frecuencias de tamaños, incluyendo en ambos casos piezas de los tamaños más grandes registrados. Los núcleos no necesariamente representan los tamaños mayores.

$\mathrm{Al}$ explorar la relación entre el tamaño de las piezas y el tipo de materia prima, no se observa diferencia marcada en los rangos de tamaños registrados para los tipos de materia prima más frecuentes (Figura 8).

En las muestras de sedimentos para el análisis de diatomeas tomadas en la cárcava, sólo se recuperaron pocos fragmentos de valvas de estos organismos, y en todos se encontraron espículas de carbón. Un testigo continuo proveniente de la laguna permitirá detectar cambios en las características ecológicas de la misma, particularmente que caractericen la disponibilidad hídrica a través del tiempo. La potabilidad del agua es un recurso primordial para los grupos humanos, por lo tanto fluctuaciones significativas en el nivel de salinidad (detectables a través de la composición de la flora de diatomeas) resultará un rasgo fundamental para contextualizar la ocupación humana en el área de la laguna.

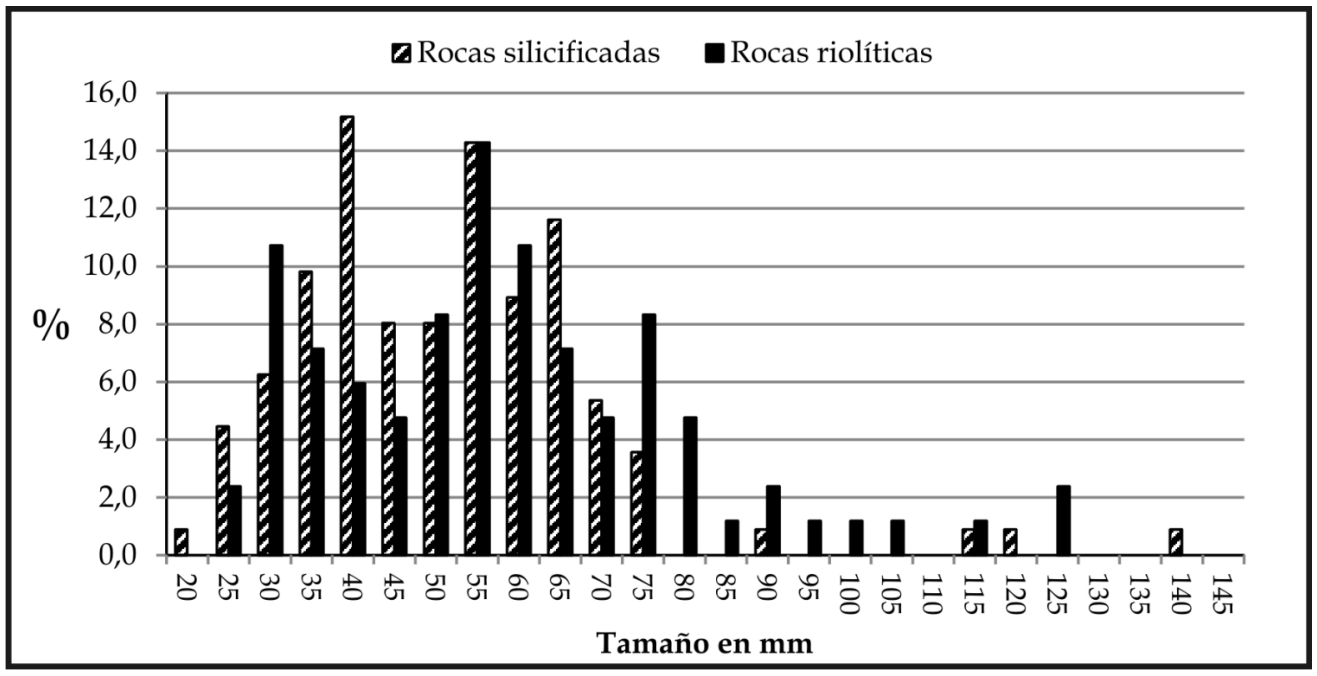

Figura 8. Tamaños artefactuales de materiales de rocas riolíticas y silicificadas en Amalia 5. 


\section{El contexto regional}

El registro arqueológico en el área de estudio presenta un rasgo distintivo: alta frecuencia de hallazgos de materiales en superficie y pocos casos de contextos en estratigrafía. Los sitios en superficie estudiados en el sector son Perro 1, Herradura 1, Avilés 1 y 3, Pozo Tierra del Fuego 2 y 3, Tres Marías, Arturo 1 y los contextos recuperados en la laguna Amalia: Amalia 1, 4, 5 y Yar Hayen (Santiago 2013; Santiago y Oría 2009; Oría 2012; Oría y Pal 2011; Oría et al. 2010a, 2010b). Entre los sitios de estratigrafía, en este sector se identificaron sólo cinco: San Julio 1 y 2 (considerado como un único sitio), La Arcillosa 2, Río Chico 1, Las Vueltas 1 y Chacra Pafoy 3 (Figura 1) (Horwitz et al. 1993/1994; Salemme et al. 2007; Santiago et al. 2007 a, 2007b; Santiago 2013); de éstos, sólo el último no ha sido aún excavado. El caso particular del sitio Las Vueltas 1 tiene un componente superficial (LV1 sup.; Santiago et al. 2009) y otro en estratigrafía (LV1 estr.; Santiago 2013). Los contextos de San Julio están caracterizados por muy escaso material lítico; se registraron 5 artefactos formatizados y 26 desechos de talla, incluyendo aquí artefactos de vidrio (Horwitz et al. 1993/1994).

Al analizar la composición lítica de los conjuntos del área de estudio (Tabla 2) se observan dos diferencias significativas entre los conjuntos de estratigrafía y los conjuntos de superficie en general: la presencia y relativa alta frecuencia de microlascas y la mayor frecuencia y

\begin{tabular}{|c|c|c|c|c|c|c|c|c|c|c|}
\hline \multirow{2}{*}{ Sitio } & \multicolumn{4}{|c|}{$\begin{array}{c}\text { Artefac tos con formatización } \\
\text { primaria }\end{array}$} & \multicolumn{2}{|c|}{$\begin{array}{l}\text { Artefacto } \\
\text { modificado por } \\
\text { el uso }\end{array}$} & \multicolumn{2}{|c|}{$\begin{array}{l}\text { Artefactos } \\
\text { con format. } \\
\text { secundaria }\end{array}$} & \multirow{2}{*}{$\begin{array}{c}\mathrm{N} \\
\text { total } \\
\text { (lítico) }\end{array}$} & \multirow{2}{*}{ Referencia } \\
\hline & $\begin{array}{l}\text { lascas y } \\
\text { láminas }\end{array}$ & $\begin{array}{l}\text { desecho } \\
\text { ind. }\end{array}$ & $\begin{array}{l}\text { micro- } \\
\text { lasca }\end{array}$ & $\begin{array}{l}\text { nú cleos } \\
\text { y nódu- } \\
\text { los }\end{array}$ & $\begin{array}{l}\text { percu- } \\
\text { tor }\end{array}$ & yunque & $\mathrm{N}$ & $\%$ & & \\
\hline LA 2 & 666 & 22 & 112 & 84 & 0 & 0 & 45 & 4,83 & 932 & Salemme et al. 2014 \\
\hline $\mathrm{RCh} 1$ & 925 & 266 & 374 & 28 & 0 & 0 & 16 & 0,99 & 1609 & Salemme et al. 2014 \\
\hline LV1 (sup.) & 302 & 99 & 10 & 7 & 1 & 0 & 19 & 4,34 & 438 & Santiago et al. 2009 \\
\hline LV1 (estr.) & 445 & 9 & 2824 & 9 & 1 & 0 & 24 & 0,72 & 3312 & Santiago 2013 \\
\hline Perro 1 & 3 & 7 & 0 & 15 & 1 & 1 & 4 & 12,90 & 31 & Santiago 2013 \\
\hline $\begin{array}{l}\text { Herradura } \\
1 \\
\end{array}$ & 223 & 70 & 17 & 111 & 2 & 0 & 23 & 5,16 & 446 & Santiago 2013 \\
\hline Avilés 1 & 96 & 13 & 0 & 37 & 3 & 0 & 18 & 10,78 & 167 & Santiago 2013 \\
\hline Avilés 3 & 597 & 125 & 4 & 20 & 1 & 0 & 35 & 4,48 & 782 & Santiago 2013 \\
\hline PTF 2 & 80 & 58 & 5 & 26 & 0 & 0 & 15 & 8,15 & 184 & Santiago 2013 \\
\hline PTF 3 & 97 & 51 & 5 & 26 & 1 & 0 & 15 & 7.69 & 195 & Santiago 2013 \\
\hline Tres Marías & 72 & 3 & 0 & 14 & 1 & 0 & 6 & 6,25 & 96 & Oría 2012 \\
\hline Amalia 1 & 35 & 18 & 0 & 10 & 0 & 0 & 6 & 8,70 & 69 & Santiago 2013 \\
\hline Amalia 4 & 60 & 20 & 0 & 20 & 0 & 0 & 29 & 22,48 & 129 & Oría 2012 \\
\hline Amalia 5 & 110 & 29 & 0 & 20 & 1 & 0 & 54 & 25,23 & 214 & Oría 2012 \\
\hline Yar Hayen & 70 & 8 & 0 & 7 & 1 & 1 & 0 & 0,00 & 87 & Oría 2012 \\
\hline Arturo 1 & 76 & 8 & 0 & 29 & 0 & 0 & 2 & 1,74 & 115 & Oría 2012 \\
\hline
\end{tabular}

Tabla 2. Composición artefactual, frecuencia y porcentaje de artefactos con formatización secundaria para los sitios del área de estudio (ind.: indiferenciado; format.: formatización

PTF: Pozo Tierra del Fuego). 
densidad de materiales en los conjuntos excavados. Sin embargo, es llamativa la similitud de los contextos estratificados y de superficie en cuanto a composición artefactual: se trata por lo general de conjuntos dominados por desechos de talla con baja proporción de artefactos con formatización secundaria, con la excepción de los sitios Amalia 4 y 5 (Tabla 2).

En relación con el uso de materias primas, las fuentes a nivel regional están conformadas fundamentalmente por rodados de arrastre glacifluvial; aunque se observó una distribución relativamente homogénea de los depósitos de estos rodados, también es posible una variación en la disponibilidad de diversos tipos de roca en distintos puntos del paisaje y/o en la forma en que se presentan los rodados para los dos tipos de materia prima (Oría 2012).

En todos los conjuntos predominan dos tipos de rocas: riolíticas y silicificadas (Tabla 3). Entre estos dos tipos de materia prima varía el predominio entre un sitio y otro, pero conservando siempre el primer y segundo lugar en representación. Es común la presencia de otros tipos de roca, como las basálticas, cuarzo, silex y sedimentitas pero siempre en muy baja frecuencia. Distintas variedades de rocas granitoides se emplean exclusivamente para la confección de bolas de boleadoras; su presencia en baja frecuencia dentro de los conjuntos refleja su uso solo para este tipo de artefactos.

\begin{tabular}{|c|c|c|c|c|c|c|c|c|c|c|}
\hline \multirow[t]{2}{*}{ Sitio } & \multicolumn{2}{|c|}{$\begin{array}{l}\text { Rocas } \\
\text { Riolíticas }\end{array}$} & \multicolumn{2}{|c|}{$\begin{array}{c}\text { Rocas } \\
\text { Silicificadas }\end{array}$} & \multirow{2}{*}{$\begin{array}{c}\text { Rocas } \\
\text { Basál- } \\
\text { ticas }\end{array}$} & \multirow{2}{*}{ 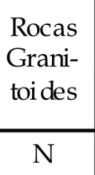 } & \multirow{2}{*}{$\begin{array}{c}\text { Otros } \\
\left({ }^{*}\right)\end{array}$} & \multirow{2}{*}{$\begin{array}{l}\text { Ind. } \\
\mathrm{N}\end{array}$} & \multirow{2}{*}{$\begin{array}{c}N \text { total } \\
\text { (lítico) }\end{array}$} & \multirow[t]{2}{*}{ Referencia } \\
\hline & $\mathrm{N}$ & $\%$ & $\mathrm{~N}$ & $\%$ & & & & & & \\
\hline $\mathrm{RCH1} 1$ & 547 & 33,9 & 675 & 41,9 & 7 & 0 & 5 & $378\left(^{(* *}\right)$ & 1612 & Santiago 2013 \\
\hline RCH1 $\left.{ }^{* * *}\right)$ & 547 & 44,18 & 675 & 54.52 & 7 & 0 & 5 & 4 & 1238 & Santiago 2013 \\
\hline LV1 (sup.) & 320 & 73,1 & 48 & 11,0 & 28 & 1 & 8 & 33 & 438 & Santiago et al. 2009 \\
\hline LV1 (estr.) & 213 & 6.4 & 92 & 28 & 164 & 1 & 4 & $28388^{(* *)}$ & 3312 & Santiago 2013 \\
\hline LV1 $\left.{ }^{* * *}\right)$ & 213 & 43,6 & 92 & 18,9 & 164 & 1 & 4 & 14 & 488 & este trabajo \\
\hline Perro 1 & 18 & 58,1 & 4 & 129 & 1 & 3 & 4 & 1 & 31 & Santiago 2013 \\
\hline Herradura 1 & 184 & 41,3 & 122 & 27,4 & 67 & 9 & 44 & 20 & 446 & Santiago 2013 \\
\hline Avilés 1 & 87 & 52,1 & 46 & 27,5 & 24 & 2 & 2 & 6 & 167 & Santiago 2013 \\
\hline Avilés 3 & 181 & 23,1 & 528 & 67,5 & 63 & 0 & 5 & 5 & 782 & Santiago 2013 \\
\hline PTF2 & 40 & 21,7 & 94 & 51,1 & 21 & 2 & 13 & 14 & 184 & Santiago 2013 \\
\hline PTF 3 & 30 & 15,4 & 145 & 74,4 & 10 & 0 & 1 & 9 & 195 & Santiago 2013 \\
\hline Tres Marías & 24 & 25,0 & 67 & 69,8 & 0 & 2 & 3 & 0 & 96 & Oría 2012 \\
\hline Amalia 1 & 39 & 56,5 & 15 & 21,7 & 9 & 1 & 0 & 5 & 69 & Santiago 2013 \\
\hline Amalia 4 & 45 & 34,9 & 53 & 41,1 & 18 & 0 & 2 & 11 & 129 & Oría 2012 \\
\hline Amalia 5 & 84 & 39,3 & 112 & 52,3 & 0 & 4 & 4 & 10 & 214 & Oría 2012 \\
\hline Yar Haven & 83 & 95,4 & $\underline{4}$ & 4,6 & 0 & 0 & 0 & 0 & 87 & Oría 2012 \\
\hline Arturo 1 & 72 & 62,6 & 30 & 26,1 & 8 & 0 & 4 & 1 & 115 & Oría 2012 \\
\hline
\end{tabular}

Tabla 3. Materias primas registradas en los sitios estudiados en el área. Valores expresados en frecuencias y porcentaje en los casos de las rocas más frecuentes. Referencias: Ind.: indeterminada; RCH: Río Chico; LV: Las Vueltas; PTF: Pozo Tierra del Fuego; *: incluye silex, cuarzo, obsidiana verde y sedimentita; ${ }^{* *}$ : el valor tan alto se debe a las microlascas (Tabla 2); ${ }^{* *}$ : valores recalculados sin las microlascas. 


\section{Discusión}

La composición artefactual y los tipos de materia prima registrados en el sitio Amalia 5 lo encuadran en las características de lo observado y descripto a nivel regional, pero a la vez muestra ciertas diferencias. Los tipos de rocas más empleados son las riolíticas y las silicificadas; la mayor representación de estas últimas no se explica por el grado de fragmentación, ya que las rocas más afectadas -aunque la diferencia no es marcada- son las riolíticas (Figura $7 b$ ). Tampoco existe diferencia en el grado de explotación de las mismas (Figura 7a). Sin embargo, existe una selección de rocas silicificadas para formatización secundaria por retoques. El recurrente empleo de esta materia prima para artefactos vinculados a una tecnología más conservada, como son las raederas, el raclette y las puntas de arma, llevan a proponer un empleo diferencial para estas rocas de textura afanítica, que probablemente se relacione con la calidad de estas rocas para la talla.

Respecto a la composición artefactual, el predominio de desechos de talla es una característica descripta a nivel regional (Santiago 2013; Oría 2012), pero en Amalia 5 es alta la representación de artefactos formatizados (Tabla 2). La presencia de artefactos con un alto grado de formatización por retoques, como las raederas - todas ellas dobles - y las puntas de arma contrasta notablemente en este conjunto donde predominan lascas primarias o secundarias, y núcleos con lascados aislados, por lo general no agotados. El perfil observado en desechos y núcleos se condice con la abundante disponibilidad de materia prima en la localidad, sin embargo, la frecuencia de raederas y puntas de arma escapa a lo conocido regionalmente (Tabla 2 y referencias allí citadas).

Los contextos en estratigrafía, con claras evidencias de mayor integridad, muestran composiciones artefactuales que no difieren marcadamente en proporciones respecto de lo observado en algunos conjuntos de superficie provenientes del área de lagunas interiores (Oría 2012). Más aún, si a los fines analíticos se suprimieran del análisis las microlascas, que son las más directamente afectadas por la acción eólica y que están ausentes en los conjuntos de superficie, la situación no varía sustancialmente. Sin embargo, la composición artefactual de Amalia 5 se aparta de esta generalización por mostrar proporciones muy superiores de artefactos con formatización secundaria (Figura 9). Aún incorporando el posible porcentaje por pérdida postdepositacional estimado en función de las microlascas presentes en los sitios de estratigrafía, el porcentaje de artefactos con formatización secundaria en Amalia 5 continúa siendo significativamente superior.

Un primer análisis llevaría a sugerir que la pérdida de material afecta más a los desechos, especialmente microlascas; los conjuntos empobrecidos como consecuencia de la exposición en superficie muestran por lo general una mayor proporción de materiales grandes, como son los núcleos, percutores y/o nódulos (Borrazzo 2009; Santiago 2013). Hay concordancia al identificar que la diferencia en la proporción de este tipo de artefactos tiene su origen en procesos postdepositacionales vinculados al tamaño de las piezas, esto es: enterramiento y/o pérdida por erosión (eólica, hídrica) de materiales de menor tamaño entre los cuales predominan los desechos de talla. También existe una tendencia a seleccionar para la formatización secundaria artefactos o formas base con módulos mayores, lo cual conllevaría a una mayor frecuencia de estos artefactos en conjuntos de superficie. 


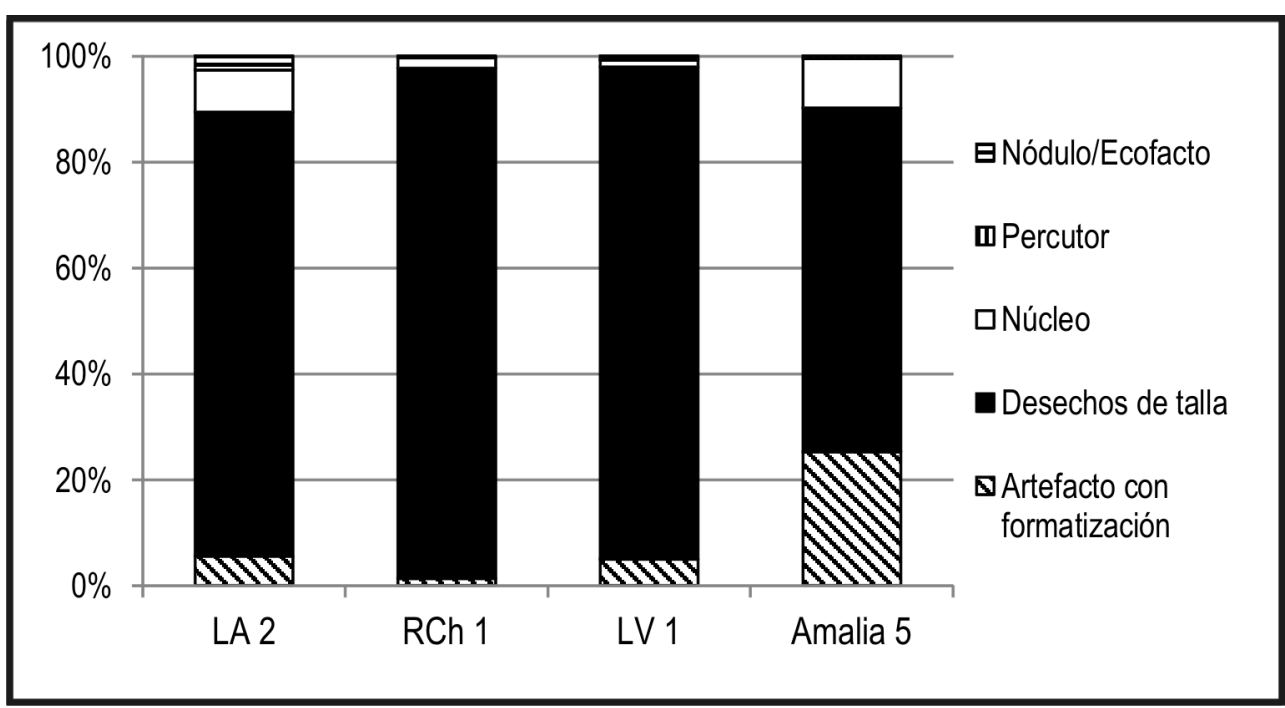

Figura 9. Comparación proporcional de las distintas categorías artefactuales representadas en los sitios en estratigrafía La Arcillosa 2 (LA2), Río Chico 1 (RCh1), Las Vueltas 1 (LV1) , comparados con Amalia 5.

En Amalia 5, lascas y artefactos con formatización secundaria comparten los mismos rangos de tamaños, incluido en ambos casos piezas de los tamaños más grandes registrados, superando algunos artefactos formatizados los tamaños registrados para lascas. La alta representación de artefactos con formatización secundaria podría explicarse como resultado de la pérdida de materiales pequeños, partiendo de la selección de lascas grandes para su formatización. Los tamaños artefactuales presentes en el sitio y los tipos de lascas registrados son concordantes con esta observación, mostrando ausencia de artefactos pequeños y cierto grado de selectividad en los tipos de lasca empleados en la formatización (Figura 6). Sin embargo, como se mencionara en el párrafo anterior y se evidencia en la Tabla 1, el tipo de materia prima seleccionada para la formatización por retoques, la roca silicificada, no presenta módulos de tamaño necesariamente mayores (Figura 8). Por lo tanto, la alta proporción de artefactos con formatización secundaria no podría explicarse únicamente por la vía de la preservación diferencial de artefactos por tamaño típica de los contextos de superficie. Las altas frecuencias de este tipo de artefactos podrían indicar un patrón cultural de descarte recurrente de artefactos en espacios puntuales, lo que a su vez sugeriría la ocupación recurrente de estos espacios.

En términos de dinámica ocupacional, las posibles explicaciones para esta situación de sobre-representación de artefactos con formatización secundaria podrían ser:

- sitios destinados a la producción, uso y/o descarte de estos artefactos, en especial raederas; es decir sitios donde se desarrollaron actividades múltiples;

- conjuntos resultantes de una acumulación de sucesivos eventos de ocupación, en los cuales la pérdida de materiales es altamente significativa ${ }^{3}$.

La primera hipótesis, si bien posible, sería un caso muy particular en base al conocimiento actual del registro arqueológico del norte de Tierra del Fuego. Aunque existen contextos con altas frecuencias de artefactos formatizados, las proporciones en relación al 
resto del conjunto difieren de lo conocido a nivel regional; por lo tanto, la situación de acumulación de artefactos depositados a lo largo del tiempo resulta la explicación más plausible en este caso. Se trataría de un "promedio de hallazgos": la acumulación de eventos de depositación aislados pero muy recurrentes, lo cual explica -comparado con otros contextos- la mayor abundancia de artefactos formatizados en relación a los desechos de talla. No se trataría de eventos de talla o formatización necesariamente, pero sí de depositación de este tipo de artefactos ${ }^{4}$. De acuerdo con el registro descripto, se plantea que Amalia 5 fue un espacio de varias reocupaciones de carácter efímero, con poca agregación de materiales (ver Figura 3a por densidades) y, posiblemente, de corta duración. Durante estas ocupaciones se desarrollaron actividades variadas, que incluyen eventos de talla evidenciados por la presencia de núcleos, lascas primarias y percutores; y otros tipos de tareas que llevaron al descarte de raederas por un lado y puntas de arma y bolas de boleadora por otro.

Otros sitios identificados en laguna Amalia -Amalia 1 y 2 (Santiago 2013), Amalia 4, 5 y Yar Hayen (Oría 2009, 2012) han aportado evidencias tanto de reocupación en el ámbito de la laguna como del uso particular de este espacio lagunar. Tal es el caso del sitio taller Yar Hayen - sitio taller, único de este tipo conocido en el área - (Oría y Pal 2011) y Amalia 4, donde se registró una punta de obsidiana verde (Oría et al. 2010a), que permite vincular, a partir de este sitio, a esta localidad con una red de contactos con otros grupos durante el Holoceno tardío 5 . Esto se relaciona y le brinda solidez al concepto de espacio cargado de significación (lugar) y de "stopping point" que permite comprender por qué un espacio determinado, en este caso laguna Amalia, se encuadra dentro de las estrategias de movilidad a nivel regional.

La mayor proporción de artefactos con formatización secundaria registrada en Amalia 5 - también observada en Amalia 4 (Oría et al. 2010a; Oría 2012) - resulta un indicador de utilización recurrente de determinados espacios. Otros rasgos destacables de la localidad Amalia además, son la mayor densidad de hallazgos en relación con contextos de superficie en otras localidades ubicadas entre los valles de los ríos Chico y Grande (Oría 2012), mayor variabilidad de materias primas y tipos artefactuales, artefactos formatizados sobre materias primas que no fueron trabajadas en el sitio, presencia de materias primas alóctonas (obsidiana verde) y variabilidad en tipos de punta de arma, todo lo cual se suma la evidencia de reactivación (Figura 3c y 4 b y c) en determinados tipos de artefactos. Toda esta evidencia permite sugerir que la laguna Amalia fue durante al menos el Holoceno tardío un espacio atractivo para las recurrentes visitas de grupos cazadores-recolectores.

En el norte de Tierra del Fuego determinados puntos (sitios o localidades) pueden caracterizarse como nodos ocupacionales en el sector costero de la estepa fueguina, a partir de la disponibilidad de algún recurso o rasgo topográfico como atractor. Los Chorrillos, La Arcillosa y Punta María son loci de grandes dimensiones y gran potencia, para los cuales se plantea la ocupación intensa y el uso recurrente (Borrero 1985; Ratto 1991; Borella et al. 1996; Salemme y Bujalesky 2000; Muñoz 2002; Salemme et al. 2007; Horwitz 1995; Favier Dubois 2001; Martin et al. 2004), registrándose ocupaciones no sólo en un mismo sitio puntual, sino en sectores aledaños, muy próximos. Se infiere que la disponibilidad de recursos debió haber influido en la elección y el uso reiterado de estos espacios. En Los Chorrillos, por ejemplo, la oferta de materia prima lítica en la playa de bermas cercana (Franco y Borrero 1999), la frecuencia de episodios de varamiento de cetáceos, los 
bancos de moluscos (estos últimos como recurso inmóvil y predecible), debieron alentar las visitas a este sector (Borella y Favier Dubois 1994-1995). El registro en la localidad Los Chorrillos evidencia entonces un uso reiterado del espacio, que es genérico y no puntual (Horwitz 1995), y que llevan a proponerlo como nodo ocupacional en el ámbito costero, al menos para el Holoceno tardío.

Hacia el interior del área, la localidad Tres Arroyos (Figura 1) constituye un nodo en el paisaje, que ha congregado grupos humanos desde finales del Pleistoceno (Massone et al. 1993). Se encuentra ubicada en un sector del paisaje con disponibilidad de agua y reparos bajo aleros rocosos, que debieron funcionar como atractores en los distintos periodos de ocupación. La cercanía espacial y cronológica de los fogones del sitio Tres Arroyos 1 para momentos tempranos (Massone 2003) y las dataciones de algunas improntas de chozas para momentos tardíos (Massone et al. 1993), demuestran que no hubo sincronicidad en la ocupación sino reincidencia en el uso de este espacio.

Coincidentemente, en el sitio Las Vueltas 1, Santiago (2013) propone la existencia de lugares que fueron utilizados de forma reiterada a través del tiempo.

Como resultado de las prospecciones sistemáticas en el interior de la estepa fueguina, en el sector comprendido entre los ríos Chico y Grande, las lagunas resultaron ser el único ambiente en el cual se observó variabilidad en relación al uso del espacio. Prácticamente en todas las lagunas se registró material en superficie; sin embargo, mientras en algunas localidades los hallazgos son escasos, en otras lagunas se registró gran cantidad de material aislado con relativo alto índice de riqueza artefactual y de materias primas, concentraciones y sitios, que permiten proponer recurrencia ocupacional, tal como ocurre en las costas este y sur de laguna Amalia. Si bien en esta localidad hasta el momento no se obtuvieron edades radiocarbónicas que permitan definir una secuencia de ocupación - como sí es el caso de Los Chorrillos en la costa - la recurrencia es visible en la densidad y estructura del registro y en la comparación entre ésta y otras localidades geomorfológicamente equivalentes del área en estudio.

En relación al uso del espacio, el norte de Tierra del Fuego ha sido caracterizado como de alta movilidad, con mínima redundancia en el uso de loci específicos, con excepción de determinados emplazamientos costeros, como los cabos y morros (Borrero 1985). Evidencias de reocupación en otros sectores costeros y en determinados puntos localizados hacia el interior ofrecen un panorama más complejo sobre el uso del espacio en el norte de Tierra del Fuego (Borrazzo et al. 2008; Santiago 2013; Morello et al. 2012).

Las evidencias aquí presentadas demuestran que también hacia el interior hay un uso predominante de determinados espacios. Las densidades artefactuales registradas en este sector no alcanzan el volumen conocido en el sector litoral marítimo, pero al enfocar el análisis únicamente hacia el interior, surgen puntos en el paisaje que sin duda reúnen características particulares en términos ambientales. Sin embargo, si bien existen numerosas lagunas que puedan funcionar como stopping points, o, en otras palabras, varios espacios cuya configuración paisajística denote una oferta de recursos similar, en la laguna Amalia el registro arqueológico apunta a un uso diferencial de la misma. 


\section{Consideraciones finales}

Las costas de la laguna Amalia constituyeron, para los cazadores-recolectores, un rasgo destacable en el paisaje, algo más que un espacio lagunar que reúne determinados recursos. La recurrencia con que fueron ocupadas sus costas queda de manifiesto en la variedad y complejidad de los registros relevados. Algunos sitios, como Yar Hayen, resaltan el rol de las lagunas como fuentes de materia prima aprovechada por los grupos humanos que habitaron la estepa; pero otro tipo de evidencia registrada también en Amalia destaca el rol particular en la percepción del espacio que debieron tener dichos grupos. El conjunto lítico de Amalia 5 aquí presentado suma una evidencia más que permite proponer la recurrencia ocupacional en este espacio, evidencia que no se halló en el resto de las lagunas.

En este sentido, laguna Amalia puede considerarse un lugar con particular significación para las poblaciones de cazadores que habitaron la estepa fueguina. Fue un espacio recurrentemente visitado, tal como surge de las evidencias presentadas: reutilización de artefactos, una tasa relativamente alta de descarte de objetos poco frecuentes en otros contextos -incluso los de estratigrafía-, artefactos costosos en términos del trabajo invertido en su confección, tal como las puntas de arma, a lo cual se suma el registro de una materia prima alóctona (obsidiana verde), que remite a la integración de redes sociales amplias a nivel regional y con significativa importancia como bien de intercambio. Posteriores estudios han de enfocarse en la oferta de recursos, la ubicación espacial de la localidad, cuestiones vinculadas a preservación y formación de sitio, dinámica ambiental, caracterización paleoambiental a partir de estudios diatomológicos y otros bioproxys, entre otros, con el fin de dilucidar las motivaciones que alentaron el uso particular de esta laguna y las recurrentes visitas a este lugar.

Agradecimientos: A la Dra. N. Pal y a E. Cena por su ayuda en el trabajo de campo. A M. Bitsch, encargado de la Ea. San Julio, por su hospitalidad. A la Dra. M. Alvarez por sus sugerencias en relación al análisis del material lítico. Al Lic. M. Vázquez por su lectura crítica a este manuscrito. Este trabajo ha sido financiado por los proyectos PICT 200538096 y PIP 0422-10. Las autoras son las únicas responsables de lo aquí expresado.

\section{Notas}

1 Se define "interior" con un criterio de distancia a la costa, considerando la descripción para ubicar el sitio San Julio 2: "lejos de la costa y de las llanuras aluviales llenas de vegas/ lagunas/y pastos ricos" (Horwitz et al. 1993-94: 397). Otras localidades han sido consideradas "interior" siguiendo criterios diferentes a los aquí empleados, por ejemplo, C ${ }^{\circ}$ Los Gatos, $\mathrm{C}^{\circ}$ Bandurrias, Lag. Las Mandíbulas, todos ellos en bahía San Sebastián. Sin embargo, la distancia a la costa de estas localidades no supera los $5 \mathrm{~km}$, por lo tanto en esta discusión han sido contempladas como costeras.

2 Pudiendo llegar a miles de piezas removidas del conjunto total si se calcula en base a las proporciones de artefactos formatizados para conjuntos de estratigrafía, particularmente Río Chico 1 (Santiago et al. 2007b; Oría 2009).

3 Esta aseveración se basa en la ausencia de la evidencia de redepositación de otro tipo de material -sea removido por erosión o por enterramiento-; por lo tanto, no es posible proponer que las actividades de talla se hayan desarrollado en el locus.

4 La laguna Amalia se ubica geográficamente en posición central en el ámbito estepario, siendo la obsidiana verde procedente del sector de mares interiores, al norte del Estrecho de Magallanes (Oría et al. 2010a). 


\section{Bibliografía citada}

Aragón, E. y N. Franco

1997 Características de las rocas para la talla por percusión y propiedades petrográficas. Anales del Instituto de la Patagonia (Ser. Cs. Humanas) 25: 187-199.

Aschero, C.

1975 Ensayo para una clasificación morfológica de artefactos líticos aplicada a estudios tipológicos comparativos. Ms. Informe CONICET. Buenos Aires.

Borella, F. y C. Favier Dubois

1994-95 Observaciones tafonómicas en la Bahía San Sebastián, costa norte de Tierra del Fuego, Argentina. Palimpsesto. Revista de Arqueología 4: 1-8.

Borella, F., L. A. Borrero y M. A. Cozzuol

1996 Los restos de cetáceos en el sitio Punta María 2. Costa atlántica de Tierra del Fuego. Arqueología Revista de la Sección Prehistoria 6, 143-158.

Borrazo, K.

2009 El uso prehistórico de los afloramientos terciarios en la Bahía San Sebastián (Tierra del Fuego, Argentina). Arqueología de Patagonia: una mirada desde el último confin (ed. por M. Salemme, F. Santiago, M. Álvarez, E. Piana, M. Vázquez y M.E. Mansur), tomo 1, pp. 291306. Ushuaia.

2010 Arqueología de los esteparios fueguinos. Tecnología y tafonomía lítica en el norte de Tierra del Fuego. Tesis doctoral, Facultad de Filosofía y Letras, UBA.

Borrazzo K., F. M., Martin R. Barberena y L. A. Borrero

2008 Geografía cultural y circulación humana en el norte de Tierra del Fuego. Arqueología del extremo sur del continente Americano. Resultados de nuevos proyectos (comp. por L. A. Borrero y N. V. Franco), pp. 227-249. Buenos Aires.

Borrero, L.A.

1979 Excavaciones en el alero `Cabeza de León’. Isla Grande de Tierra del Fuego. Relaciones de la Sociedad Argentina de Antropología XIII: 255-271.

1985. La economía prehistórica de los habitantes del norte de la Isla Grande de Tierra del Fuego. Tesis doctoral, Facultad de Filosofía y Letras, UBA.

2008. Early occupation in the southern Cone. Handbook of South American Archaeology (ed. por Silverman, H., Isbell, W. H.), pp. 59-77. New York.

Borrero, L. A. y M. Casiraghi

1980 Excavaciones en el sitio Bloque Errático 1 (San Sebastián, Tierra del Fuego). Relaciones de la Sociedad Argentina de Antropología XIV (1): 129-146.

Borrero, L. A., M. Casiraghi y M. I. Hernandez Llosas 1981 Arqueología del norte de la Isla Grande de Tierra del Fuego. Revista del Museo Territorial 1:1-23.

Coronato, A., Fanning, T., Salemme, M., Oría, J., Pickard, J., J. F. Ponce

2011. Aeolian sequence and the archaeological record in the fuegian steppe, Argentina. Quaternary International, 245: 122-135 
Dunnell, R. C. y W. Dancey

1983. The siteless survey: A regional scale data collection strategy. Advances in Archaeological Method and Theory 6 (ed. por M. Schiffer): 267-287. New York.

Favier Dubois C. M.

2001. Análisis geoarqueológico de los procesos de formación del registro, cronología y paleoambientes, en sitios arqueológicos de Fuego-Patagonia, Tesis doctoral, Facultad de Filosofía y Letras, UBA.

Franco, N.V.

2002. Estrategias de utilización de recursos líticos en la cuenca superior del río Santa Cruz (Argentina). Tesis doctoral, Facultad de Filosofía y Letras, UBA.

Franco, N.V. y L.A. Borrero

1999. Metodología de análisis de la estructura regional de recursos líticos. En los tres reinos: prácticas de recolección en el Cono Sur de América (ed. por C., Aschero, M.A. Korstanje y P.M. Vuoto), pp. 27-37. Tucumán.

Horwitz V. D.

1995. Ocupaciones prehistóricas en el sur de Bahía San Sebastián (Tierra del Fuego, Argentina). Arqueología 5: 105-136.

Horwitz V., Borrero L. y Casiraghi M.

1993/1994. Estudios arqueológicos en San Julio 2 (Tierra del Fuego). Relaciones de la Sociedad Argentina de Antropología XIX: 391-416.

Martin, F., R. Barberena y R. Guichón

2004. Erosión y restos humanos. El caso de la localidad Chorrillos, Tierra del Fuego. Magallania 32: 125-142.

Massone, $\mathrm{M}$.

1987. Los cazadores paleoindios de Tres Arroyos (Tierra del Fuego). Anales del Instituto de la Patagonia (Serie Cs. Sc.) 17: 47-60.

1997. Prospección arqueológica del sector comprendido entre los ríos Marazzi y Torcido, zona norte de Tierra del Fuego. Anales del Instituto de la Patagonia (Serie Cs. Hs.) 25: 123-136. 2003. Fell 1 Hunters' hearths in the Magallanes Region by the end of the Pleistocene. Where the South Winds Blow, Ancient evidence of Paleo South Americans (ed. por L. Miotti, M. Salemme y N. Flegenheimer), pp. 153-159. Texas.

Massone M., Jackson D. y A. Prieto

1993. Perspectivas arqueológicas de los Selk'nam. Centro de Investigaciones Diego Barros Arana, Santiago, Chile, Dirección de Bibliotecas, Archivos y Museos.

Morello F., L. Borrero, M. Massone, Ch. Stern, A. García-Herbst, R. McCulloch, M. ArroyoKalin, E. Calás, J. Torres, A. Prieto, I. Martinez, G. Bahamonde y P. Cárdenas 2012. Hunter-gatherers, biogeographic barriers and the development of human settlement in Tierra del Fuego. Antiquity 86: 71-87.

Muir R.

1999. Approaches to landscape. Macmillan Press LTD. 
Muñoz, A. S.

2002 La explotación de Mamíferos por cazadores-recolectores terrestres de Tierra del Fuego. Tesis doctoral. Facultad de Filosofía y Letras, UBA.

Ocampo C. E. y P. Rivas

1996. Caracterización arqueológica preliminar del suroeste de la Tierra del Fuego. Anales del Instituto de la Patagonia (Serie Cs. Hs.) 24: 125-151.

Oliva G., L. González, P. Rial y E. Livraghi.

2001. Áreas Ecológicas de Santa Cruz y Tierra del Fuego. Ganadería Ovina Sustentable en la Patagonia Austral. INTA. Río Gallegos.

Oría J.

2009. Prospecciones en el interior de la estepa fueguina. Arqueología de Patagonia: una mirada desde el último confín (ed. por M. Salemme, F. Santiago, M. Alvarez, E. Piana, M. Vázquez y M.E. Mansur), pp. 1109-1125. Ushuaia.

2012. Patrones de movilidad pre europeos en el norte de Tierra del Fuego. Una perspectiva geoarqueológica. Tesis doctoral. FCN\&M, UNLP.

Oría J. y N. Pal.

2011. Integridad y estrategias de producción lítica en un sitio de cazadores-recolectores de la estepa fueguina: Yar Hayen (Tierra del Fuego, Argentina). Werkén 14: 137-154.

Oría J., Salemme M. C. y F. C. Santiago

2010a. Obsidiana verde en la estepa fueguina: un hallazgo en Amalia 4. Magallania 38 (2): 201-207.

Oría J., Salemme M., Santiago F. y A. Montes

2010b. Localidad Tres Marías: un caso para evaluar la pérdida de información arqueológica por erosión eólica en la estepa fueguina. Cazadores-Recolectores del Cono Sur 4: 159-173.

Orquera L. y E. Piana

1986. Normas para la descripción de objetos arqueológicos de piedra tallada. CADIC, Contribución Científica (Publicación especial) N¹, Ushuaia.

Paulides, L.

2006. El núcleo de la cuestión. El análisis de los núcleos en los conjuntos líticos. El modo de hacer las cosas. Artefactos y ecofactos en arqueología (ed. por C. Pérez de Micou), pp. 67-99. Facultad de Filosofía y Letras UBA.

Prieto, A., E. Calás, F. Morello y J. Torres

2007. El sitio arqueológico Myrén 2, Tierra del Fuego, Chile. Magallania 35 (2): 89-103.

Ramos, M. y J. Merenzon

2004. Ensamblajes, tecnología y análisis espacial del primer componente de Túnel I. Temas de Arqueología, Análisis lítico (comp. por A. Acosta, D. Loponte y M. Ramos), pp. 145-191. 
Ratto N.

1991 Análisis funcional de las puntas de proyectil líticas del sitio Punta María 2 (Tierra del Fuego). Shincal 3 (3): 171-177. Publicación especial en adhesión al X CNAA, San Fernando del Valle, Catamarca.

Salemme M. C. y G. Bujalesky

2000 Condiciones para el asentamiento humano litoral entre Cabo San Sebastián y Cabo Peñas (Tierra del Fuego) durante el Holoceno medio. Desde el país de los gigantes. Perspectivas arqueológicas en Patagonia (ed. J. B. Belardi, F. Carballo Marina y S. Espinosa), tomo II, pp. 519-531. Río Gallegos, UNPA.

Salemme M. C., Bujalesky G. G. y F. C. Santiago

2007 La Arcillosa 2: La ocupación humana durante el Holoceno Medio en el Río Chico, Tierra del Fuego, Argentina. Arqueología de Fuego-Patagonia. Levantando piedras, desenterrando huesos... y develando arcanos (ed. por F. Morello, M. Martinic, A. Prieto y G. Bahamonde), pp. 723-739. Punta Arenas, Chile.

Salemme M., Oría J., Turnes L. y F. Santiago

2014 Caracterización tecnomorfológica de dos conjuntos líticos del Holoceno medio en la estepa fueguina: La Arcillosa 2 y Río Chico 1. Revista del Museo de Antropología 7(1): 39-54.

Santiago, F.

2013 La ocupación humana en el norte de Tierra del Fuego durante el Holoceno medio y tardío. Su vinculación con el paisaje. Editora Cultural Tierra del Fuego, Ushuaia.

Santiago F. C., G. G. Bujalesky y M. Salemme

2007a Prospección arqueológica en la cuenca del Río Chico, Tierra del Fuego, Argentina. Arqueología de Fuego-Patagonia. Levantando piedras, desenterrando huesos... y develando arcanos (ed. por F. Morello, M. Martinic, A. Prieto y G. Bahamonde), pp. 357-363. Punta Arenas, Chile.

Santiago F., Oría J. y M. Salemme

2007b. Nuevo contexto arqueológico del Holoceno medio. Río Chico 1. Tierra del Fuego, Argentina. XVI Congreso Nacional de Arqueología Argentina. Tras las Huellas de la Materialidad. Actas III: 439-445. San Salvador de Jujuy.

Santiago, F., N. Pal y M. Salemme

2009 Análisis tecno-morfológico Y funcional del material lítico de superficie del sitio Las Vueltas 1 (norte de la Isla Grande de Tierra Del Fuego). Relaciones de la Sociedad Argentina de Antropología XXXIV: 231-250.

Santiago, F., Salemme, M., Suby, J. y R. Guichón

2011 Restos óseos humanos en el norte de Tierra del Fuego. Aspectos contextuales, dietarios y paleopatológicos. Intersecciones en Antropología 12: 115-166.

Saxon E.

1976. La prehistoria de Fuego - Patagonia: colonización de un hábitat marginal. Anales del Instituto de la Patagonia 7: 63-73. 
Stafford C. R.

1995. Geoarchaeological perspectives on paleolandscapes and regional subsurface archaeology. Journal of Archaeological Method and Theory 2 (1): 69-104.

Stafford C. R. y E. R. Hajic

1992. Landscape scale: geoenvironmental approaches to prehistoric settlement strategies. Space, Time, and Archaeological Landscape (ed. por J. Rossignol y L. Wandsnider), pp. 137-161. Nueva York.

Tilley C.

1994 A phenomenology of landscape. Places, paths and monuments. Berg publishers Oxford (UK) y Providence (USA).

Urrejola Dittborn, C.

1971 Isla Grande de Tierra del Fuego (Bahía Inútil) Informe Arqueológico. Boletín de Prehistoria de Chile 3 (4): 121-133. 